\title{
Impact of Road Infrastructure Investments on the Structural Competitiveness of the Burkina Faso Economy
}

\author{
Sigue Moussa \\ Department of Economics and Management, University Ouaga II, Ouagadougou, Burkina Faso \\ Email address: \\ msigue.reche@gmail.com \\ To cite this article: \\ Sigue Moussa. Impact of Road Infrastructure Investments on the Structural Competitiveness of the Burkina Faso Economy. International \\ Journal of Economic Behavior and Organization. Vol. 8, No. 3, 2020, pp. 64-73. doi: 10.11648/j.ijebo.20200803.13
}

Received: July 31, 2020; Accepted: August 17, 2020; Published: August 27, 2020

\begin{abstract}
This paper assesses the impact of road infrastructure investments on the structural competitiveness of Burkina Faso's economy over the period 1980 to 2015. The methodology adopted presents, on the one hand, the endogenous growth theory as a theoretical reference framework and, on the other hand, exposes the direct and indirect effects of public infrastructure spending on the performance of the economy. After conducting preliminary tests, an Error Correction Model $(\mathrm{ECM})$ and the results reveal that investment in road infrastructure positively and significantly affects the structural competitiveness of the country's economy. However, this impact varies over time. Indeed, the elasticity of structural competitiveness with respect to road investments is 0.06 in the short term and 0.32 in the long term. In view of these results, the economic policy implication that emerges is that an increase in road infrastructure investment is a policy of increasing the structural competitiveness of the country's economy.
\end{abstract}

Keywords: Structural Competitiveness, Investment in Public Infrastructure, Burkina Faso

\section{Introduction}

Spending on transport infrastructure in general and road infrastructure in particular are considered as key instruments for promoting the structural competitiveness of the economy since the roads pave the way for structural transformation of economies. In fact, for an economy to develop and for wealth to be generated and distributed, people and goods must be able to move. As pointed out by Inger, the economy's dynamism depends on the movement of people, goods and services and these movements in turn depend on the existence of quality transport infrastructure [1].

Despite the ever-growing interest of the economic literature in the study of the competitiveness of economies, it must be emphasized that this is one of the least understood concepts on which there is no unanimous vision on both its definition and determinants. However, we define structural competitiveness as the capacity of the national economy to impose itself on the domestic and external markets with the aim of improving the living conditions of the populations. In this perspective, structural competitiveness refers to the ability of the national economy to create and maintain an environment that supports the creation of more wealth for the economy and more prosperity for people. In fact, a competitive economy aims to improve average per capita income over the long term.

An examination of the economic literature reveals that the question of the productive role of road infrastructure expenditure has been renewed, thanks in particular to the developments of endogenous growth theorists. From the development of Meade through thas of Aschauer to those of Barro and Kopp, spending on road infrastructure are considered an essential tool to have quality road infrastructure capable of providing optimal spatial coverage so as to create both direct and indirect effects on economic productivity gains [2-6].

Particularly in Burkina Faso, the geographical reality makes it a country in the grip of a constraint of isolation. As a result, the country is seeking road infrastructure to conduct its trade. In doing so, it undertook important reforms between 1992 and 2009 to modernize its road transport sector to make it more productive and competitive.

Despite these reforms, Burkina Faso still has a low 
coverage of its road network, road infrastructure of lower quality and poorly distributed in space. Also, the country remains less competitive. According to the Banque Mondiale, the poor quality of road infrastructures in Burkina Faso means that the cost of road transport remains high compared to some the West African Economic and Monetary Union (WAEMU) countries [7]. Indeed, per kilometer of road, Burkina Faso records 55 F.CFA against 31 F.CFA for Cote d'Ivoire and 34 F.CFA for Mali. For the author, this situation does not favor a gain in economic competitiveness for the country. In agreement with the MID et MT, this situation could be partly due to the poor performance of road infrastructure and partly to the poor spatial distribution of road infrastructure, which poses a problem of regional accessibility especially in rural areas [8]. In this regard, the data analysis of the MIDT reveals that out of the thirteen (13) regions of the country, the Center and Hauts Bassins regions were the best equipped paved roads in 2013 [9]. The percentages of paved roads in the total classified road network of these regions are respectively $50.90 \%$ and $43.41 \%$. Added to this, in 2013 paved roads were in the order of $52.34 \%$ for national roads, $2.14 \%$ for regional roads and only $0.87 \%$ for departmental roads [9]. Land roads accounted for $47.66 \%$ for national roads, $97.86 \%$ for regional roads and $99.13 \%$ for departmental roads [9]. Also, the Banque Mondiale in its report on competitiveness in Africa reveals that among WAEMU member countries, Burkina Faso is one of the countries with the least developed road infrastructure and also the lowest Global Competitiveness Index (GCI) [10]. Indeed, the country recorded between 2011 and 2015 an average GCI of 3.23 against 3.7 for Senegal, 3.68 for Ivory Coast, 3.58 for Benin and 3.41 for Mali. Regarding the quality of road infrastructure over the same period, the ranking of the Banque Mondiale shows that after the Ivory Coast and Senegal are removed, Mali and Benin were the top third and fourth grades roads [10]. As for Burkina Faso, it obtained the lowest quality of road infrastructure over the period 2011-2015.

But while in general the impact of road infrastructure investments on competitiveness is undoubted, very few studies exist in Burkina Faso. For this country, the literature on the specific role of road infrastructure investments in the country's structural competitiveness remains rather limited. Most of the authors who have been interested in the road infrastructure question of road infrastructure have studied their influence on the transport chain [11, 12]. However, the [7, 13, 12, 14] found that investment in transport infrastructure in general and road infrastructure in particular is a key instrument for increasing the growth country's economy. However, these authors emphasize that the expenditure on road infrastructure is not made optimally. Therefore, they do not allow tent good coverage of Burkina Faso road network, which would explain the poor spatial distribution of road infrastructure.

The overall objective of this article is to make a quantitative assessment of the impact of road infrastructure investments on the structural competitiveness of Burkina
Faso's economy. More specifically, it is a question of assessing the long-term relationship between road infrastructure expenditure and economic competitiveness and of analyzing the contribution of road infrastructure investments to the country's commercial performance in the WAEMU space.

\section{Theoretical Approach of the Role of Public Infrastructure Spending in Economic Performance}

\subsection{Theoretical Frame}

The theoretical framework referential retained in this article is the theory of endogenous growth. Indeed, economic models dealing with the role of public infrastructure spending in general and road infrastructure spending, particularly in the competitiveness of the economy, are based on the endogenous growth model. In this context, the role of road infrastructure in the competitiveness of economies is based on an analysis of the determinants of economic growth. This framework explains the mechanism by which improved public infrastructure investment can increase factor productivity and ensure strong economic competitiveness. Here, spending on road infrastructure is likely to play directly on the stock of road infrastructure in the short term and therefore on the productive capacity of the economy. In the long term, the indirect effects of road investments can record a gain in overall productivity.

It was not until the work of Aschauer to observe a rereading of the contribution of infrastructure spending to economic performance [3-4]. His work laid the foundation for an explosion of new endogenous growth models which now consider investing in public infrastructure as a selfsustaining growth factor productivity and competitiveness in the long term. Among these developments, the reference model is that of [5]. This model makes it possible to highlight the role of the road transport chain in the competitiveness of the economy. In this chain, road infrastructures intervene as well in the sphere of production as in that of marketing. When road infrastructure is poor or inefficient, this leads to higher direct transport costs and longer delivery times, which significantly increases trade costs and thus reduces competitiveness. Later, Barro et Sala-I-Martin have shown that public infrastructure spending plays a leading role in improving the marginal productivity of private factors which, in short, enhance the overall productivity of the economy [15]. Therefore, an improvement in investments in infrastructure in general and in road infrastructure in particular contributes to reducing transport costs and thus contributes to the improvement of the volume of the country's trade [16]. For Veganzones, improved investment in road infrastructure is a driving force for the competitiveness of the economy in the long term [17]. 


\subsection{Direct and Indirect Effects of Public Infrastructure Spending}

In the economic literature, spending on road infrastructure is assumed to increase the productivity of public and private capital through its direct effects on the public capital stock and its indirect effects on improving overall productivity. In this model, any expenditure in road infrastructure allows, either the building of new roads or to maintain existing ones. Road infrastructure can thus contribute to economic growth through increased trade, which in turn promotes specialization and allows for economies of scale and comparative advantages. This argument was developed by Smith who gave the mechanisms [18]. His idea is based on the idea that improving road infrastructure reduces the cost of transporting raw materials and thus the costs of production, which makes it possible to offer low selling prices and to improve regional and interregional trade. In fact, according to the author, quality road infrastructures favor the improvement of the transport system which results in lower transport costs and a reduction in distances between the different localities.

This representation highlights the multiplier effect of expenditure on road infrastructure. Indeed, the construction of new roads makes use of the branch of Buildings and Public Works (BPW). However, this branch employs a large volume of labor and therefore distributes income. Thus, the transmission mechanism of road investment to the productive capacity of the economy can be broken down as follows: the increase in investment causes an increase in employment, especially in the construction industry, which in turn increases consumption distributed income, and consumption increases the productive capacity of the economy. Moreover, in the logic of the Keynesian multiplier, the increase of investment in road infrastructures entails effects of propagation of this investment on the productive capacity of the national economy. Road construction and maintenance is therefore a preferred tool to have direct effects on the productive capacity of the economy.

However, this transmission mechanism has limits in most developing countries like Burkina Faso. Indeed, the increase in employment generates additional income. These incomes partly increase the demand for imported consumer goods, which in fact contributes very little to the productive capacity of local industries.

Abraham summarizes to a number of four, the direct effects of road investments on the competitiveness of the economy [19]. For him, an investment in road infrastructure produces in the short term the following consequences:

1) reduction in traction expenses: a road investment makes it possible to ensure the availability of quality roads, helping to reduce the consumption of fuels, lubricants and tires. Also, it helps to slow the wear of rolling stock;

2) saves time: an investment in road infrastructure helps to reduce waiting times and then contributes to the increase in average journey speed;
3) Improving safety: new road investments reduce the number of accidents per vehicle-kilometer and consequently reduce the severity of accidents;

4) Increased road capacity: This is probably the direct effect of the most obvious road investment. The construction or maintenance of a section of road allows in the short term to increase the capacity of the road in terms of traffic.

In terms of long-term indirect effects, they are generally the product of short-term direct effects. They increase the competitiveness of the economy by causing both a spatial diffusion of externalities (external economies and productivity gains) and an attraction of new activities.

The construction of a road is synonymous with the acquisition of sustainable public capital as an "appropriate factor" to increase the productivity of the economy [20]. On the economic side, the expenses incurred for the construction and maintenance of the roads are justified by the fact that they facilitate the production process in the short and long terms by ensuring a better circulation of products and factors of production and by improving trade relations between economies. Thus, investment in road infrastructure is considered as a source of external savings by Barro and Tefra since it reduces the decrease in marginal productivity of traditional factors and consequently generates returns to scale $[5,21]$.

The role of road infrastructure in spreading externalities across regions has been established through several approaches. Many of these approaches have highlighted the triggering nature of the regions' commercial performance. In fact, Creightney states that, in general, access to the regions is all the easier in terms of cost and time as the road infrastructure is developed [22]. For him, the accessibility of rural areas in general is more difficult because of the weakness or lack of quality road infrastructure. As a result, increased investment in road infrastructure connects with other economies, increasing trade intensity between these regions. Focusing on road transport in rural areas, Sirima and al. supports the hypothesis that road infrastructure is a source of regional diffusion of externalities by noting that regional potentialities, constituting the driving force in the analysis of Reggiani, are sources of the provision of road infrastructure $[12,23]$. For him, the difference in the economic performance of the regions within the same country lies essentially in their respective levels of accessibility.

\section{Methodological Approach}

The methodological approach aims at defining the econometric model, the variables as well as the source of the data that are used in this work

\subsection{Specification of the Theoretical Model}

The theoretical model chosen is an extension of Barro model [5]. This model considers spending on road infrastructure as a self-sustaining factor of private factor productivity and overall productivity. Thus, starting from 
Kopp, the competitiveness gain model is given by:

$$
\frac{d \rho}{\rho}-\frac{d \bar{\rho}}{\bar{\rho}}=S_{G}^{*} \frac{d G}{G}-S_{\bar{G}}^{*} \frac{d \bar{G}}{\bar{G}}+\varepsilon
$$

In the equation $\rho$ indicates the overall productivity gain, $S_{G}^{*}$ represents the contribution of road infrastructure spending to productivity gains, $G$ infrastructure spending country roads, $\bar{G}$ infrastructure spending road and competing countries and $\varepsilon$ the error term [6].

The left-hand side of the equation represents the difference in productivity gain between Burkina Faso and WAEMU's competing countries. If this term is positive, it shows that the country has a greater competitiveness face to its competitors. The right-wing member, on the other hand, shows the difference between the elasticity of overall productivity in relation to Burkina Faso's road infrastructure investment and that of its WAEMU competitors. According to Kopp, the share of $G$ in $\bar{G}$ is all the greater as the ratio between the expenditures made by the country compared to its competitors is high [6]. For him, if investments in road infrastructure are productive, it would seem logical that the country that invests more in road infrastructure benefits more than competing countries. These benefits are measured by the productivity gain or the level of competitiveness.

\subsection{Presentation of the Variables}

As Rousse has pointed out, theoretical developments in measuring the structural competitiveness of an economy in the aggregate sense are rare and relatively new [24]. However, several indicators measure structural competitiveness in the macroeconomic sense. But it should be noted that each indicator is established according to the focus of the study and that, in general, each indicator used to assess the competitiveness of the economy depends on the facts highlighted in the definition of concept. As a result, the relative income gap is used as an indicator of structural competitiveness in this article.

Structural competitiveness is equivalent to the capacity of the national economy to improve living conditions of the population by creating an important part of wealth compared to that of its competitors in the Union. Thus, the relative income gap makes it possible to compare the country's per capita income as a percentage of that of its main competitors. In addition, the relative income gap is a proxy for the productivity gap in the equation above.

The relative income gap is obtained from the following equation:

$$
E R R=\frac{G D P_{b f}-G D P_{p c}}{G D P_{p c}}
$$

With ERR the relative income gap, $G D P_{b f}$ Burkina Faso's constant price real GDP and $G D P_{p c}$ constant prices average real GDP of Burkina Faso's competitors in the WAEMU. The latter is obtained by performing a weighted average of the real GDP of the competing countries of Burkina Faso in WAEMU. The main purpose of weighting is to take into account the weight of each economy in the Union.
In agreement with Rousse, the factors that may affect the structural competitiveness of an economy are those that affect its external and internal performance [24]. These variables can therefore be grouped according to the export rate and the foreign penetration rate. In this work, two groups of variables are retained. On one side there is the variable of interest and on the other side there are the control variables.

The variable of interest is:

Investment in road infrastructure: it represents all the expenditures for the construction, maintenance and technical operation of the road network. It is also equivalent to the transportation price for the community. An increase in investment in road infrastructure contributes to a certain extent to lowering the cost of road transport borne by the carrier and therefore a reduction in the transport price per unit of traffic. In the short term, it improves the stock of public capital, the productivity of the transport function and generates a multiplier effect. In the long term, indirect effects help to improve the productive structure and commercial performance of the economy and hence its competitiveness. The expected theoretical sign is therefore positive.

Despite the richness of the literature presented above, we are far from knowing all the factors that affect the structural competitiveness of the economy. To solve this problem, it is important to limit oneself to the factors that directly affect commercial performance [25]. Thus, in addition to the variable of interest, other variables are retained under the label of control variables likely to affect the structural competitiveness of the economy through its commercial performance component. This is the:

export rate: it represents the share of exports by volume in real GDP. This variable captures the share of GDP devoted to meeting foreign demand. According to Bceao, an increase in this rate means that the country's competitive position is favorable [26]. Otherwise, an increase in the export rate results in a higher market share abroad and a better external competitiveness. The expected sign is positive.

rate to foreign penetration: It is measured by the ratio of imports and absorption. Domestic demand is used as a proxy for absorption. An increase in the foreign penetration rate indicates a drop in performance, acquired in the domestic market. For cons, the low rate induces a gain in competitiveness in the domestic market. The expected sign is negative.

\section{Data Source}

The data used in this article are essentially secondary and cover the period from 1980 to 2015, which is thirty-six years (36) years and come from two databases. Data on the share of investment in road infrastructure in the total investment budget were collected from Burkina Faso Infrastructure Minstry. The relative income gap, the export rate and the foreign penetration rate come from the West African States Central Bank (WASCB) database. 


\section{Hypothesis Tests and Presentation of the Econometric Model}

In the presence of time series, several preliminary tests are necessary. This is mainly the normality of errors, the stationarity of series and their cointegration.

\subsection{Normality Test}

Given the dynamics of investments in road infrastructure and that of the competitiveness of the economy, it is necessary to verify the normality of the errors in order to have reliable statistics to perform Student's tests on the parameters of the model. The test of Jarque, based on asymmetry and flattening, makes it possible to check the normality of the errors [27]. Based on the assumption of the normality of the errors against the alternative hypothesis of their non-normality, the result of the test gave a probability of 0.64 . Since this probability is greater than 0.05 , the null hypothesis of normality of residues is not rejected. Thus, this empirical evidence makes it possible to conclude that the errors are normal and this allows the continuation of the tests on the time series.

\subsection{Stationarity Analysis}

The analysis of a time series requires, at first, the study of the stationarity of the variables concerned. This section develops the two most used tests for stationarity studies. In order to appreciate the stationarity of the studied series, we apply the ADF test of Dickey and Fuller and that PP of Philips $[28,29]$. The ADF test makes it possible to take into account the correlation between the different series and that PP improves the ADF test by providing a correction to the nonparametric test, correlation and heteroscedasticity problems. The combination of these two tests makes it possible to have more appropriate results since when a variable is stationary in level for the ADF test and as a first difference for the PP test, it is the PP test which is retained. The hypothesis that is tested is the presence of a unit root against the alternative hypothesis of the stationarity of series. The result of these two tests indicates that all the series are stationary in first difference. Thus, they are integrated of order 1 .

$$
\Delta E R R_{t}=\beta_{1} \Delta I n v_{t}+\beta_{2} \Delta T e_{t}+\beta_{3} \Delta T p e_{t}+\lambda\left(E R R_{t-1}-\beta_{4} I n v_{t-1}-\beta_{5} T e_{t-1}-\beta_{6} T p e_{t-1}-\beta_{0}\right)+\epsilon_{t}
$$

The equation can model both short-term and long-term dynamics. In other words, it represents the ECM that is estimated in this work. As a result, the parameter $\lambda$ must be negative and meaningful so that there is a return of $E R R_{t}$ to its long-term equilibrium value. The recall force indicates a catch-up possibility that allows for a long-term relationship between road infrastructure investments and the competitiveness of the economy.

\subsection{Estimation Method}

For the estimation of the ECM, the approach adopted is the one-step estimation of [32]. In contrast to Granger two-step

\subsection{Cointegration Test}

The study of cointegration aims to identify the true relationship between series by looking for the existence of a cointegrating vector and eliminating its effect, if necessary. The idea of cointegration is needed and shared by all in macroeconomic analysis because it is an approach that derives from the multidimensional model of unit root systems.

In the application of the cointegration test, it is first necessary to establish the order of integration of the variables. This is because cointegration is only possible for nonstationary variables. To determine the number of cointegration relationships, Johansen proposes two tests based on the eigenvalues of a matrix derived from a two-step calculation [30]. The first test proposed by the author is that of the trace and the second is based on the maximum eigenvalue. In this work, we apply the test of the trace which consists in testing the null hypothesis of absence of cointegration, if the rank of the matrix is statistically equal to zero; against the alternative hypothesis of the presence of cointegration, if the rank of the matrix is greater than or equal to one.

Having established previously that the series were all stationary in first difference, it is now necessary to show that there is a cointegration relation between them. In other words, it is necessary to verify that in the short term the series may be divergent but in the long term, they evolve towards a balance.

The result indicates that the rank of the trace is significantly equal to one (01) at the $5 \%$ threshold. It is at this threshold that the trace begins to be lower than the critical value of the chisquare statistic. Thus, the result of Johansen trace test concludes that series are wedged with the presence of a single cointegrating vector [30]. This result reveals that, in the long run, there is an equilibrium relationship between the structural competitiveness of the economy and investment in road infrastructure. From there, it is possible to perform a representation of the error-correction model.

\subsection{Error Correction Model (ECM)}

The results of the econometric tests revealed that the series retained for the analysis are non-stationary and integrated with a single cointegrating vector. Thus, their relationship must be estimated using an error-correction model [31].

estimation, the one-step method reduces the loss of information [33]. The approach of Hendry is to jointly estimate the shortterm dynamics and long term by the ordinary least squares [32].

\section{Results and Interpretations}

In this part, it is a question of presenting the results of the estimation of the ECM, to study their validity and to interpret them.

\subsection{Results of the Estimated ECM}

The estimate of ECM gave the following result: 
Table 1. Results of ECM estimation.

\begin{tabular}{llll}
\hline Variables & Coefficients & Standards Errors & t-Student \\
\hline Diff_Inves_IR & $0.0630134^{* * *}$ & 0.0185913 & 3.39 \\
Diff_TX_EXP & $0.0242403^{* * *}$ & 0.0073125 & 3.31 \\
Diff_tx_pe & 0.0639621 & 0.1140897 & 0.56 \\
ECRR_1 & $-0.1497372^{* * *}$ & 0.0257974 & -5.80 \\
Diff_Inves_IR_1 & $0.0476044^{* * *}$ & 0.0135482 & 3.51 \\
Tx_Export_1 & $0.0853174^{* * *}$ & 0.0171359 & 4.98 \\
Tx_Pe_1 & -0.0144635 & 0.12166 & -0.12 \\
cons & $0.322374^{* * *}$ & 0.3492666 & 9.11 \\
Adjusted $R^{2}$ & 0.9149 & & \\
long term elasticities of exogenous variables & $\beta_{4}=0.32$ & & \\
& $\beta_{5}=0.57$ & & \\
\hline
\end{tabular}

*** significant at $1 \%$

Source: Author's estimate.

The MCE estimate provided a negative and significant recall force (ECRR_1). Its coefficient is -0.1497 . This result confirms the presence of a long-term relationship between economic competitiveness and spending on road infrastructure. This coefficient indicates that $14.97 \%$ of an imbalance occurred over a year are absorbed during the same year. The inverse of the absolute value of the value of the recall force gives a period equal to 6.68 years. This indicates that following a short-term imbalance caused by a shock on investment in road infrastructure, it takes about six (6) years and eight (8) months for structural competitiveness and investment in road infrastructure to find their long-term equilibrium. Also, the model is adequate since $91.49 \%$ of the variations of the structural competitiveness are explained by the selected explanatory variables.

\subsection{Validation of the Estimate}

The validation of the estimate requires the verification of certain essential tests obtained after the estimates.

\subsubsection{Overall Meaning of the Estimate}

This test is based on the null hypothesis of all coefficients against the alternative hypothesis of existence of at least one non-zero coefficients, the overall significance test gave a $\mathrm{P}$ value zero. This result makes it possible to reject the null hypothesis and to conclude easily that at the 5\% threshold, the model is globally significant.

\subsubsection{Specification Test}

Ramsey specification test makes it possible to judge the relevance of the functional form chosen [34]. This test also makes it possible to judge the absence of a relevant explanatory variable in the model as well as the correlation between competitiveness and the error term. The result of the test gave a P-value of 0.2622 . Thus, at the $5 \%$ threshold, the null hypothesis of good specification of the model is therefore not rejected. In other words, the model is well specified. Thus, it is possible to conclude in general that the functional form of the model is relevant and more particularly, that the estimated model did not omit other relevant variables that could explain the structural competitiveness of the model.

\subsubsection{Autocorrelation Test of the Series}

This test is based on the Lagrange Multiplier (LM) which checks the autocorrelation of an order greater than one (01). The null hypothesis of no autocorrelation of errors is not rejected at the 5\% significance level since the BREUSCHGODFREY LM-test provided a P-value of 0.123 . This result makes leads to the conclusion that there is no autocorrelation of the series studied.

Similarly, the application of the DURBIN-WATSON test, based on the null hypothesis of no autocorrelation of errors against the alternative hypothesis of autocorrelation, gave a probability of 0.756 . At the $5 \%$ threshold, the null hypothesis is not rejected and this confirms a lack of autocorrelation of the errors previously obtained.

\subsubsection{Heteroscedasticity Test}

The test of White, built around the null hypothesis of homoscedasticity of errors against the alternative hypothesis of heteroscedasticity, gave a P-value of 0.4192 [35]. At the $5 \%$ threshold, the null hypothesis is not rejected. This empirical evidence leads to the conclusion that there is homoscedasticity of errors.

\subsubsection{Endogeneity Test}

For this test, the procedure of Nakamura and Nakamura was adopted [36]. In agreement with these authors, it is initially a question of regressing the investment in road infrastructures on the other explanatory variables of the model and to recover the residues. In a second step, the recovered residues are introduced into the estimation of the structural competitiveness. Road infrastructure investment is endogenous when the "residual" variable is significantly correlated with structural competitiveness. The result of the appendix of the test leads to the rejection of the hypothesis of endogeneity between investment in road infrastructure and the relative income gap since its coefficient is not significant.

\subsubsection{Stability Test}

This test help assessing the stability of the model over time for forecasting purposes. The null hypothesis that is tested is the instability of the model against the alternative hypothesis, its stability. The results of the CUSUM and CUSUM square 
tests show that the curves are both included in the corridor. Therefore, the model is stable.

The various tests carried out above validate the result of the estimation of the ECM. Now, the results obtained must be interpreted.

\subsection{Interpretations of the Results}

The results of the estimation show that in the short and long term, the investment in road infrastructure and the export rate significantly and positively affect the structural competitiveness of Burkina Faso's economy.

1) Impact of investment in road infrastructure

The estimation results show that spending on road infrastructure has a positive effect on the structural competitiveness of Burkina Faso's economy, whether in the short or long term. Table 2 shows the elasticity of the structural competitiveness of the economy relative to investment in road infrastructure in the short and long term.

Table 2. Comparison of short-run and long-run elasticities.

\begin{tabular}{lll}
\hline Period & Short term & Long term \\
\hline Elasticity & 0.06 & 0.32 \\
\hline
\end{tabular}

Source: author.

The comparison of elasticities shows that investment in road infrastructure positively affects structural competitiveness in the short term and in the long term. An increase in investment in road infrastructure of $1 \%$ improves the structural competitiveness of the economy by $0.06 \%$ in the short term and by $0.32 \%$ in the long run, all other things being equal. Thus, it is in the long term that investment in road infrastructure has a greater impact on structural competitiveness.

This result confirms the hypothesis of the dynamics of the contribution of road infrastructure investments to the structural competitiveness of the economy and corroborates the hypotheses of the endogenous growth theories of [5]. The explanation of this result lies in the specificity of the road infrastructure. Indeed, following a shock on road infrastructure investment, positive externalities and the spatial diffusion of externalities take time to promote the transformation of the structure of Burkina Faso's economy. In the present case, this time is estimated to six years and eight months.

2) Contribution of the export rate

The ECM estimate has established that the export rate affects the structural competitiveness of the economy in the short and long term. It represents a key factor in promoting the structural competitiveness of Burkina Faso. This result is in line with economic theory which establishes a positive relationship between a country's export rate and its external performance. Moreover, it is established that the increase in investments in road infrastructure ensures in the short term, a better accessibility to the regions and thus a better circulation of products and in the long term, a transformation of the structure of the economy.
As a reminder, the export rate of the economy measures the share of the country's exports in its real GDP. Its growth is synonymous of a rise in market share abroad. However, an improvement in the market share abroad requires upstream a structural transformation of the economy in this case, a strengthening of the productive structure. This structural transformation takes time to take root. As Droin and Djahini have pointed out, an increase in investment in road infrastructure produces long-term driving effects, which contributes to improving the productive capacity of the economy and thus its competitiveness [37, 28]. To understand this link, it is necessary to break down the export performance following two types of factors.

On the one hand, there are the demand factors that specify the conditions of market accessibility and, on the other hand, the factors relating to the productive capacity of the economy. In terms of demand factors, improved market access is driving increased export profitability through higher value-added net exports of road transport costs. This has already been mentioned by [11]. Increasing the profitability of exports in turn contributes to the improvement of Burkina Faso's market share in the Union. Factors relating to productive capacity include the reduction in the cost of production resulting from the improvement of the productivity of the road transport sector. For this purpose, the impact of investments in road infrastructure can go even beyond the impact of capital expenditure. In sum, it is clear that by its direct and indirect effects, investment in road infrastructure increases the export rate, which in turn improves the competitiveness of the economy.

The estimation results show that the foreign penetration rate is not significant in the econometric sense. Despite its econometric non-significance, it seems useful to give economic explanations for this result.

Indeed, the foreign penetration rate measures the weight of the import in the absorption of the country. On the theoretical level, its increase reflects a decline in competitiveness, especially in the domestic market. The sign obtained by the estimate is consistent with the sign established by the theoretical literature but the variable remains insignificant. A decomposition of the import of Burkina Faso shows that over the period 1980-2015, that from the WAEMU area accounted for only $9.24 \%$ of the total import against $90.76 \%$ from the zone outside WAEMU [39]. This means that in its domestic market, domestic production competes with products from the WAEMU zone. Therefore, imports from EU countries do not pose a threat to local production; which justifies the nonsignificance of this factor.

\subsection{Discussion of Results}

It has been established through the results of the estimations that the increase of road investment in Burkina Faso is a source of gain of structural competitiveness of the economy. The purpose of this section is to perform a crosssectional analysis of the results obtained in order to draw similarities or controversies to those of other authors if necessary. To achieve this, it seems to us indispensable to put 
the results obtained in a logic of analysis of the various ways in which the improvement of road investments affects the competitiveness of the economy.

\subsubsection{Effects on Existing Traffic and Induction of New Traffic by Lowering Costs}

The effects on traffic are the main effects observed in the short and medium term of an investment in road infrastructure. The improvement of road investments makes induces an "economic surplus", essentially related to the reduction of the cost of road transport, an immediate result of the decrease in travel time, the increase of safety and the reinforcement of 'accessibility. Overall, road investment induces two types of road traffic. On one side there is the traffic derived representing the traffic and other modes of transport or other routes, and is constituted by freight traffic, attracted to the newly developed road infrastructure. This traffic appears in a relatively short time. On the other hand, there is the induced traffic. In this case, it concerns the traffic of goods which is carried out thanks to the facilities offered by the road investment whereas it did not take place because of the absence of the road infrastructures, their bad quality or the cost of high road transport. These effects partly explain the elasticity of competitiveness in relation to investment in road infrastructure in the short term.

\subsubsection{Effects Related to Economic Flows}

Knowledge of the effects of road investment on structural competitiveness is likely to come from increased economic flows. These economic flows are the result of a short-term improvement in the productivity of the transport branch described above.

Our results indicate that in Burkina Faso's case, the economy takes time to integrate all the effects of investment in road infrastructure. The time required is estimated at six years and eight months. Thus, it is only after this time that the investment in road infrastructures allows the national economy to have an integral productive capacity and to improve its external position. Improving external competitiveness requires effective interaction between the sphere of production, marketing and consumption.

Indeed, in Burkina Faso, like the other WAEMU countries, the spatial coverage of the road network is low. The vast majority of asphalt roads are moving towards large urban centers to the detriment of rural areas. However, it is the latter that supply the major industries with raw materials (usually from the primary sector).

\subsubsection{Stimulation Effects and Long-Term Impact}

In view of the estimation result, and following the reasoning of Kopp, investments in road infrastructure are undoubtedly productive for Burkina Faso [6]. In other words, the investment in road infrastructure has the effect of stimulating the development of the national economy, or even to completely change the economic structure through the strengthening of its productive capacity and "train" it towards a structurally competitive economy. Long-term stimulus and impact effects are most often the end result of all short-term direct effects.

The comparison of short-term and long-run elasticities has indicated that investment in road infrastructure affects the structural competitiveness of Burkina Faso's economy more in the long term than in the short term. The long-run elasticity is 0.32 versus 0.06 for the short term. In any case, the results obtained by Charmeil, Nubukpo and Tefra, show that, in the short term, an improvement in road investments automatically leads to an improvement of the road infrastructure stock which in turn stimulates the demand for goods, the distribution of income thanks to the jobs created, the road traffic of merchandise [40, 21, 41]. All of these effects contribute in the short term to improving the accessibility and commercial performance of the economy.

In the long term, on the other hand, all the effects observed in the short term combine to ensure a diffusion of externalities and to favor the emergence of the external economies which make it possible to maintain the productivity of the capital and labor factors over time. Therefore, the long term is marked by a greater impact of investment in road infrastructure on the structural competitiveness of Burkina Faso's economy. As Charmeil pointed out, it is in the long term that investments in road infrastructure act the most and most often on the competitiveness of economies [40].

Moreover, it appears generally that road investment positively impacts the structural competitiveness of the Burkina Faso economy over the period 1980-2016. This conclusion is similar to that of [41]. Indeed, the author who was interested in the effects of public spending on the economic growth of WAEMU showed that for public investment expenditure in transport infrastructure in general, the impact is positive.

\section{Conclusion}

At the end of this work, the overall result obtained is plausible and highlights the positive impact of road infrastructure investments on the structural competitiveness of Burkina Faso's economy in WAEMU. Investment in road infrastructure contributes to improving the structural competitiveness of the Burkina Faso economy, notably through the mobility of goods, external economies and increased accessibility to regions and the Union market.

Estimates of long-term and short-term relationships have shown that investing in road infrastructure improves competitiveness in the longer term rather than in the short term. Thus, it appears that structural competitiveness is more determined by the indirect effects of investment in road infrastructure.

The analysis carried out may give rise to what could be an economic policy implication for improving the structural competitiveness of the Burkina Faso economy in the WAEMU area. As has been established, road infrastructure is the most important transport infrastructure in Burkina Faso and its effects on the economy far exceed their mere ownership of public spending. In this context, what role can 
the public authorities play?

To strengthen the structural competitiveness of Burkina Faso's economy, the State must first and foremost reinforce the optimal allocation of investment in road infrastructure with a view to having sufficient and good quality linear routes, generating training in the sphere of production and marketing. Regarding the future, the country must focus its investment efforts on improving the quality of its road infrastructure, a guarantee of an improvement in its structural competitiveness. This is more of a necessity since 2012; the share of road investment in total investment has hardly reached $5 \%$ of the total public investment budget.

\section{References}

[1] Inger, A. (2013, Novembre 12). Tout commence par la route. Récupéré sur www.banquemondiale.org: http://www.banquemondiale.org/fr/news/opinion/2013/11/12/I t-all-starts-with-a-road.

[2] Meade, J. E. (1952). External Economies and Diseconomies in a Competitive Situation. Economic Journal.

[3] Aschauer, D. A. (1989a). Is public expenditure productive? Journal of monetary Economics, 23, pp 177-200.

[4] Aschauer, D. A. (1989b). Public Investment and Productivity Growth in the Group of Seven. Economic Perspectives, pp 1725.

[5] Barro, R. J. (1990). Gouvernment spending in a simple model of endogenous growth. Journal of Political Economy, pp 125130.

[6] Kopp, A. (2007). Incidence des investissements routiers sur la productivité macroéconomique-réevaluation du cas de l'Europe Occidentale. OCDE/CEMT de recherche sur les transports, pp 79-102.

[7] Banque Mondiale. (2009). Rapport sur le développement dans le monde. Banque mondiale.

[8] MID et MT. (2011). Actualisation de la stratégie de developpement du secteur des transports au Burkina Faso. Ouagadougou: MIDT.

[9] MIDT. (2015). Programme d'investissement public gestion 2015. Ministère des Infrastructures du Désenclavement et des Transports.

[10] Banque Mondiale. (2015). Rapport sur la compétitivité en Afrique. Banque mondiale.

[11] Sirpe, G. (1994). Le transport routier de marchandises au Burkina Faso: un essai d'analyse économique. Ouagadugou: CEDRES ETUDES.

[12] Sirima, B., Monga, C., Bambara, D., Pare, N., Savadogo, K., N'Cho-Oguie, C., and Charleir, F. (2001). Competitiveness and Economic Growth: policies, strategies and actions. Ouagadougou: Ministry of Economy and Finance of Burkina Faso.

[13] Sirpe, G. (2003). Transport routier et ecoulement des produits agricoles: une analyse économique de l'influence des transports routiers sur les mouvements interrégionaux de céréales au Burkina Faso. Ouagadougou: Press Universitaires de Ouagadougou.

[14] Christel, A., et AFUA, E. (2010). Coûts du transport et de la logistique sur le corridor Tema-Ouagadougou. Agence Américaine pour le Developpment International (USAID).

[15] Barro, R. J., et Sala-I-Martin, X. (1996). la croissance économique. Collection sciences économiques, MCGRAWHILL/EDISCIENCE.

[16] Limao, N., and Venables, A. Y. (1999). Infrastructure, Geographical Disadvantage and Transport Costs. The World Bank.

[17] Veganzones, M. A. (2000). Infrastructures, investissement et croissance: un bilan de dix années de recherches. CERDI, 143.

[18] Smith, A. (1776). An Inquiry into the Nature and Cause of the Wealth of Nations. Oxford University Press.

[19] Abraham, C. (1961). L'étude économique des investissements routiers. Révue économique.

[20] Henner, H. F. (2000). Infrastructure et développement un bilan. CERDI, 1-15.

[21] Tefra, M. (1996). Economie des transports. Université de Lille I: Ellipses.

[22] Creightney, C. P. (1993). Transport and Economic Performance: A Survey of Developing Countries. World Banque.

[23] Reggiani, A. (1999). Accessibility, trade and locational behaviour. Ashgate.

[24] Rousse, E. H. (1992). Les performances extérieures de la France et de l'Allemagne: l'effet de l'investissement sur la compétitivité. Economie et statistique.

[25] Lachaal, L. (2001). La compétitivité: Concepts, définitions et applications. Institut National de la Recherche Agronomique de Tunis (INRAT), 29-36.

[26] Bceao. (2015). Rapport sur la compétitivité des économies de l'UEMOA en 2012. BCEAO.

[27] Jarque, C. M., and Bera, A. K. (1984). Testing the Normality Assumption in Limited Dependant Variable Models. International Economic Review.

[28] Dickey, D., and Fuller, W. (1981). Likelihood ratio statistics for autoregressive time series with unit root. Econometrica, 49 (4).

[29] Philips, P., and Perron, P. (1988). Testing for Unit root in Time Series Regression. Biometrika.

[30] Johansen, S. (1988). Statistical analysis of cointegration vectors. Journal of economic dynamics and control, 12, pp 231-254.

[31] Bourbonnais, R. (2011). Econométrie. DUNOD.

[32] Hendry, D. F. (1980). Econometrics: Alchemy or Science? Economica.

[33] Granger, C. W. (1983). Co-integrated Variales and Errorcorrecting Models. Université de San Diego: Document de travail. 
[34] Ramsey, J. B. (1969). Test for Specification Errors in Classical Linear Least Squares Regression Analysis. Journal of the Royal Statistical Society, 350-371.

[35] White, H. (1980). A Heteroskedasticity-consistent covariance estimateur and a direct test for heteroskedasticity. Econometrica.

[36] Nakamura, A., and Nakamura, M. (1981). On the Relationships Among Several Specification Error Tests Presented by Durbin, Wu and Hausman. Econometrica.

[37] Droin, J. C. (1991). Les routes dans les zones tropicales et désertiques. Ministère de la coopération et du désenclavement.
[38] Djahini, E. (2015). The Main Determinants of International Competitiveness in Sub-Saharan Africa. Munich Personal RePEC Archive, 1-27.

[39] Bceao. (2016, 07 18). Base de données. Récupéré sur Banque Centrale des Etats de l'Afrique de l'Ouest - www.bceao.int: http://www.bceao.int

[40] Charmeil, C. (1967). Les investissements routiers à operer d'ici vingt-cinq ans et leur incidence prévisible sur le volume de l'activité économique. Revue économique, 1-12.

[41] Nubukpo, K. K. (2003). Dépenses publiques et croissance des économies de l'UEMOA. CIRAD, 1-29. 